\title{
A STUDY ON THE CAUSES OF STRATEGIES FAILING TO SUCCESS
}

Mehmet Ali KÖSEOĞLU

Mehmet BARCA

Kemal KARAYORMUK

\author{
Menderes EDAS, Turkey \\ Sakarya University, Turkey \\ Afyon Kocatepe University, Turkey
}

\begin{abstract}
This study attempts to investigate the reasons behind the failure of implementing strategies. The failure of the strategies is evaluated according to results of their formulation and implementation processes. In order to find out the reasons behind the failure of the strategies, questionnaires were administered to 418 managers. In light of the findings, the reasons behind the failure of the strategies seem mostly to stem from the formulation process, and the most important issues in the implementation process are found out to be organizational, individual, and managerial.
\end{abstract}

Key Words: Strategy, Formulation, Implementation, Turkey

\section{INTRODUCTION}

This study focuses on the causes of strategies not leading to success. A study conducted by Fortune magazine revealed that $90 \%$ of the strategies are unsuccessful, and single most important cause of this is believed to be the weak application of the strategies (Waterman, et al. 1988). Although it has been widely acceptedthat the change is necessary for the growth of organizations, more than $70 \%$ of the change-oriented attempts in the name of change strategies are unsuccessful (Higgs \& Rowland, 2005). In addition, Raps (2004) states that the rate of successfully implemented strategies is between $10 \%$ and $30 \%$. In this respect, for both the practitioners and academicians, it seems of necessity to investigate why strategies fail to produce success that was planned to achieve.

In recent years, though there seems to be many theoretical studies on the strategy implementation process (Okumus, 2001, 2003; Okumus \& Poper, 1999) and empirical studies conducted on the implementation of successful strategies and the obstacles hindering such successful implementations, most of these studies have been conducted in developing countries (e.g. Kargar \& Blumenthal, 1994; Dooley, et al. 2000; Peng \& Litteljohn, 2001; Thorpe \& Morgan, 2007; Harrington \& Kendall, 2006; Schaap, 2006; Qi, 2005) and there is a paucity of such studies in developed countries (Alashloo, et. al, 2005; Shah,2005; Hacker \& Washington, 2004). In particular, these studies focus on successful strategy implementations, yet do not attempt to describe the obstacles confronted with during strategy implementation processes.

For successful strategy implementation, many models have been developed in the literature (Peter and Waterman, 1982, Wernham, 1984, David, 1989, Skivington \& Daft 1991, Roth et al,1991, Hrebiniak, 1992, Yip,1992, Eisenstat, 1993, Bryson \& Bromiley, 1993, Sandelands, 1994, Lingle \& 
Schieman, 1994, Okumus, 2001, Peng and Litteljohn,2001, Higgins, 2005). However, these models do not clearly discuss the extent to which the factors allowing strategies to lead to success and/or factors preventing strategies from resulting in success. That is, it has not yet been shed much light on whether the strategic formulation process or strategy implementation process is more influential in terms of strategies' resulting in success or failure. Alashloo et al. (2005) attempt to categorize the reasons for the failure of strategies under four main headings: i) Planning Consequences, ii) Organizational Issues, iii) Managerial Issues, iv) Individual issues. However, they do not deal with the question of which of these categories is more influential on the success of strategies.

In this respect, the main contribution of the present study is expected to determine the most influential factors preventing strategies from being successful, taking the four categories of factors (planning, organization, management, and individual) into account.

To this end, we selected the sampling among the firms in Turkey. With the implementation of the conditions of the free market economy as of 1980, the companies in Turkey have become more liberal and more foreign investment has come to the country, which forced the organizations to adjust themselves to emerging market conditions. These changes put Turkey among the 10 biggest developing markets. Another factor leading to the selection of sampling from Turkey is its unique cultural and historical texture. A bridge between the West and East, Turkey is a candidate country for European Union membership. These special characteristics of the country have important influences on the strategies of the organizations developed to gain a competitive advantage. On the other hand, political and economic crises experienced in the country in the last ten years have a power to direct the orientation of the organizations in the country. Hence, it is believed that the investigation of the efforts of the organizations throughout this process will reveal important results for the purpose of the present study.

Therefore, the sampling of the study consists of the managers of the organizations operating in Turkey. The questionnaire designed, which was based on the study by Alashloo, Castka and Sharp (2005) mentioned above, was administered to the top managers of the organizations selected regardless of their size.

In what follows is that the study first looks at the causes behind the failure of strategies and focuses on the obstacles encountered in the processes of strategy formulation and strategy implementation. Here, given the theoretical discussion of the causes, the hypotheses to be tested are set. Then, the results and findings of the study are discussed. In the final section suggestions for the future research are made.

\section{Strategy Implementation}

Alexander (1991) likens the strategic management process to a two-sided medallion. One side of the medallion is the strategy formulation describing the action plan that enables the organization to compete in specific situations; the other side represents the strategy implementation process describing how the formulated strategy is implemented. Hence, it can be argued that whether a strategy is successful or unsuccessful depends separately on these processes and their interaction. Namely, work performance is not only related to how well the strategies are formulated but also how well they are implemented. Indeed, unless successfully applied, even the strategy delicately designed and correctly predicted is almost valueless. While strategy formulation and application are functions closely connected to each other, implementation of the strategy is the most complex and time-consuming part of strategic management. Strategy implementation covers almost every aspect of the management and it needs to be started from many different points within the organization (Shah, 2005). Though the 
reason for the failure of strategies is viewed to be strategy implementation process in the strategic management literature, this issue has attracted less attention than the issue of strategic formulation in research (Webster, 1981, Kargar \& Blumenthal, 1994). Alexander (1991) gives the reasons behind this fact as follows: strategy implementation is less glamorous than strategy formulation; many academics and practitioners tend to overlook it because of a belief that anyone can do it; people are not exactly sure what strategic management process includes, where it begins and where it ends; there are only a limited number of conceptual models of strategy implementation.

According to Hrebiniak (2005) the formulation-implementation relationship is as such: "Still, it is obvious that the execution of strategy is not merely as clear and understood as the formulation of strategy. Much more is known about planning than doing, about strategy making than making strategy work". In general, in strategic management literature and in particular, in strategy literature, strategy implementation is viewed to be different from strategy formulation and it is considered to be an issue of adjusting organizational structures and systems (Aaltonen et. al 2002). Alashloo et. al., (2005) defines strategy implementation as the explanation of how the strategy developed in a limited time should effectively be implemented to the capacities, human and financial resources of the organization. According to Reid (1989), strategy implementation is a vital process describing the opportunities of the future. From another viewpoint, strategy implementation is the collection of implementations and operations originating from the important managerial capabilities and behaviours defined for good leadership (de Kluyver \& Pearce, 2003). Shah (2005) defines strategy implementation as the implementation of strategy formulation to determine the future direction of the organization. Parnell (2008) explains strategy implementation through the concepts of participation, conception, and commitment that affect the dissemination of the strategy. As it can be seen in these definitions, strategy implementation is a complex process (Schellenberg, 1983).

It is really difficult to come up with an exact definition of strategy implementation. Definitions of strategy implementation are shaped according to strategy formulation, elements of organizational behaviours and its importance for the organization. Another complex issue related to strategy implementation is concerned with the factors affecting strategy implementation. There are many different opinions about this issue, which are presented in Table 1.

When we evaluate the factors affecting strategy implementation, it is seen that successful implementation of strategies is of great importance for all the organizations either private or public. Even the best strategies are useless unless they are applied well (Aaltonen et al 2002). In other words, strategy' breeding success can only be achieved through implementation. The subtle point here is that no matter how internally consistent is the strategic achievement concept, how many innovative elements has it got, how strong the organization is positioned against the rivals by it, what is most concerned about is how well it is implemented. And success of the implementation depends on the actors involved. For strategy implementation to be successful, Thompson et al (2006) proposed a 9-staged process. These are:

1. Staffing the organization with the needed skills and expertise, consciously building and strengthening strategy-supportive competencies and competitive capabilities, and organizing the work effort.

2. Creating a company culture and work climate conducive to successful strategy implementation and execution.

3. Developing budgets that steer ample resources into those activities critical to strategic success. 
4. Ensuring that policies and operating procedures facilitate rather than impede effective execution.

5. Using the best-known practices to perform core business activities and pushing for continuous improvement. Organization units have to periodically reassess how things are being done and diligently pursue useful changes and improvements.

6. Installing information and operating systems that enable company personnel to better carry out their strategic roles day in and day out.

7. Motivating people to pursue the target objectives energetically and, if needed, modifying their duties and job behavior to better fit the requirements of successful strategy execution.

8. Tying rewards and incentives directly to the achievement of performance objectives and good strategy execution.

9. Exerting the internal leadership needed to drive implementation forward and keep improving on how the strategy is being executed. When stumbling blocks or weaknesses are encountered, management has to see that they are addressed and rectified on a timely basis.

Table 1. Factors Influencing Strategy Implementation

\begin{tabular}{|c|c|}
\hline Authors & Factors \\
\hline $\begin{array}{l}\text { Peter and Waterman } \\
\text { (1982) McKinsey's 7S }\end{array}$ & Structure, style, staff, shared values, skills, system, strategy. \\
\hline Wernham (1984) & $\begin{array}{l}\text { Resources, confidence, others delivering what they promised, informa- } \\
\text { tion and back-up materials }\end{array}$ \\
\hline David (1989) & Motivation, leadership and direction skills, co-ordination \\
\hline Skivington \& Daft (1991) & Intended strategy, structure, systems, interactions, sanctions \\
\hline Roth et al (1991) & $\begin{array}{l}\text { Coordination, managerial philosophy, configuration, formalization, } \\
\text { centralization, integrating mechanisms }\end{array}$ \\
\hline Hrebiniak (1992) & $\begin{array}{l}\text { Leadership, facilitating global learning, developing global managers, } \\
\text { having a matrix structure, working with external companies }\end{array}$ \\
\hline Yip (1992) & Organizational structure, culture, people, managerial processes \\
\hline Eisenstat (1993) & Competence, co-ordination and commitment \\
\hline $\begin{array}{l}\text { Bryson \& Bromiley } \\
(1993)\end{array}$ & Context, process, outcome \\
\hline Sandelands (1994) & Commitment, time, emotion and energy \\
\hline $\begin{array}{l}\text { Lingle \& Schieman } \\
(1994)\end{array}$ & $\begin{array}{l}\text { Market, people, finance, operation, adaptability, and environmental } \\
\text { factors }\end{array}$ \\
\hline Okumus (2001) & Content, context, process, outcome \\
\hline $\begin{array}{l}\text { Peng ve Litteljohn } \\
\text { (2001) }\end{array}$ & Structural arrangements and the selection and development of key roles \\
\hline Higgins (2005) & $\begin{array}{l}\text { Strategy and purposes, structure, systems and processes, style of leader- } \\
\text { ship, staff, resources, shared values, organizational culture, and strategic } \\
\text { performance. }\end{array}$ \\
\hline Birnbaum (2007) & $\begin{array}{l}\text { Action planning; organisational structure; human resources; the annual } \\
\text { business plan; monitoring and control; the linkage- The Foundation for } \\
\text { Everything Else. }\end{array}$ \\
\hline
\end{tabular}


Feo\&Jansen (2001) suggest 10 steps for strategy implementation to be successful. These are: establish a vision, agree on a mission, develop key strategies, develop strategic goals, establish values, communicate company policies, provide top management leadership, deploy goals, measure process, review progress. Also according to Wheelen and Hunger (2006) the most important activities involved in strategy implementation are: (1) involving people from all organisational levels in strategy implementation, i.e. allocating the responsibility for strategy execution; (2) developing programmes, budgets and procedures; (3) organising for strategy implementation; (4) staffing (matching the managers and employees with the strategy); and (5) leading by coaching people to use their abilities and skills most effectively and efficiently to achieve the organisational objectives.

\section{Obstacles in front of Strategy Implementation}

The most important reason for the failure of the organization is the obstacles encountered while implementing strategies. The literature presents many problems encountered while implementing strategies (Okumup, 2001, Dobni, 2003, Dooley et al. 2000, Freedman, 2003, Beer \& Eisenstant, 2000, Hoag et al. 2002, Dobni, 2003, Galpin, 1998). For instance, Alexander (1991) mentions various reasons as obstacles: i) Implementation took more time than originally planned, ii) Unanticipated major problems arose iii) Activities were ineffectively coordinated, iv) Competing activities and crises took attention away from implementation, v) The involved employees had insufficient capabilities to perform their jobs, vi) Lower-level employees were inadequately trained, vii) Uncontrollable external environmental factors created problems, viii) Departmental managers provided inadequate leadership and direction, ix) Key implementation tasks and activities were poorly defined, $\mathrm{x}$ ) The information system inadequately monitored activities. Wessel (1993) points out many individual barriers hindering successful implementation of strategies such as, too many and conflicting priorities, insufficient top team functions, a top down management style, interfunctional conflicts, poor vertical communication and inadequate management development.

Beer \& Eisenstant (2000) see the barriers in front of strategy implementation as "six silent killers of strategy implementation" and explain them as follows: a top-down/laissez-faire senior management style, unclear strategic intentions and conflicting priorities, an ineffective senior management team, poor vertical communication, week co-ordination across functions, business or borders, and inadequate down-the-line leadership skills development.

Corboy \& O'Corrbui (1999) define the obstacles as "deadly sins of strategy implementation" and go on explaining them as follows: a lack of understanding of how the strategy should be implemented, customers and staff not fully appreciating the strategy, unclear individual responsibilities in the change process, difficulties and obstacles not acknowledge, recognized or acted upon, and ignoring the day-to-day business imperatives.

In addition, according to Giles (1991) there are three reasons why poor strategic planning is an obstacle to strategy implementation: i) a strategy is not really a strategy but "a mixture of budgets and management wish list"; ii) a strategy is not executable; and 3) the executors do not accept the strategy as "their own" because they did not participate in its formulation.

Alashloo et al. (2005) subsumes the obstacles in front of strategy implementation under four headings. These are planning consequences, organizational issues, managerial issues and individual issues. Furthermore, they delineate what each heading consists of (Table 2). 
Table 2. The Impeders of Strategy Implementation

\begin{tabular}{|c|c|c|c|}
\hline No & Impeders & No & Impeders \\
\hline $\mathbf{P}$ & Planning consequences & $\mathbf{O}$ & Organizational Issues \\
\hline P1 & Lack of exact strategic planning & $\mathrm{O} 1$ & $\begin{array}{l}\text { Incompatible structure with the strat- } \\
\text { egy }\end{array}$ \\
\hline $\mathrm{P} 2$ & Insufficient linking of the strategy to goals. & $\mathrm{O} 2$ & Unsuitable resources allocation \\
\hline P3 & Time limitation & $\mathrm{O} 3$ & Lack of adequate communication \\
\hline P4 & Lack of consensus among decision makers & $\mathrm{O} 4$ & Lack of effective co-ordination \\
\hline P5 & Lack of identification of major problems & O5 & Lack of adequate information system \\
\hline P6 & Lack of effective role formulators & O6 & Incompatible organizational culture \\
\hline P7 & Unsuitable training system & $\mathrm{O} 7$ & Competing activities among people \\
\hline P8 & Unclear regulation and executive policies & O8 & Competing activities among units \\
\hline P9 & Lack of choice of real strategy & O9 & $\begin{array}{l}\text { Unsuitable evaluation and control } \\
\text { systems }\end{array}$ \\
\hline \multirow[t]{3}{*}{ P10 } & Lack of a national attitude to strategy & $\mathrm{O} 10$ & Unsuitable compensation system \\
\hline & & $\mathrm{O} 11$ & Inadequate physical facilities \\
\hline & & $\mathrm{O} 12$ & Lack of increative system \\
\hline $\mathbf{M}$ & Managerial Issues & I & Individual issues \\
\hline M1 & Unsuitable leadership & I1 & $\begin{array}{l}\text { Lack of enough capabilities of em- } \\
\text { ployees }\end{array}$ \\
\hline M2 & Lack of adequate organizational support & $\mathrm{I} 2$ & Resistance to change among people \\
\hline M3 & Lack of adequate manager commitment & I3 & Resistance to change among units \\
\hline M4 & Fear of insecurity among managers & I4 & Fear of insecurity in the new territory \\
\hline M5 & Political factors in regard to power & I5 & Lack of understanding of the strategy \\
\hline M6 & Unsuitable personnel management & I6 & Inadequate connection to the vision \\
\hline M7 & Uncontrollable factors & I7 & $\begin{array}{l}\text { Lack of enough motivation of em- } \\
\text { ployees }\end{array}$ \\
\hline M8 & Lack of enough motivation among the managers & I8 & Lack of employee commitment \\
\hline
\end{tabular}

Alashloo et al.(2005) categorization seems to be not only very comprehensive but also very operational in order to find out the relative importance of the obstacles in the processes of strategy development and application. Therefore, the categorization is taken for granted for this study.

\section{Hypotheses}

In Taslak' s (2004) study of 112 textile firms in Turkey, the reasons behind the failure of strategies are sought, yet this study does not indicate whether strategy formulation or strategy implementation is more influential on the success of strategies. In addition in Turkey managers are more affiliated with strategy planning than strategy implementation and evaluation (Dinçer et. al 2006). According to the literature review, following hypothesis and structural equity model was generated. 
Hypothesis 1: The factors relating strategy implementation process is more influential than those of strategy formulation process in explaining strategic failure.

Hypothesis 2: The obstacles in front of the strategy implementation mostly stem from individual factors.

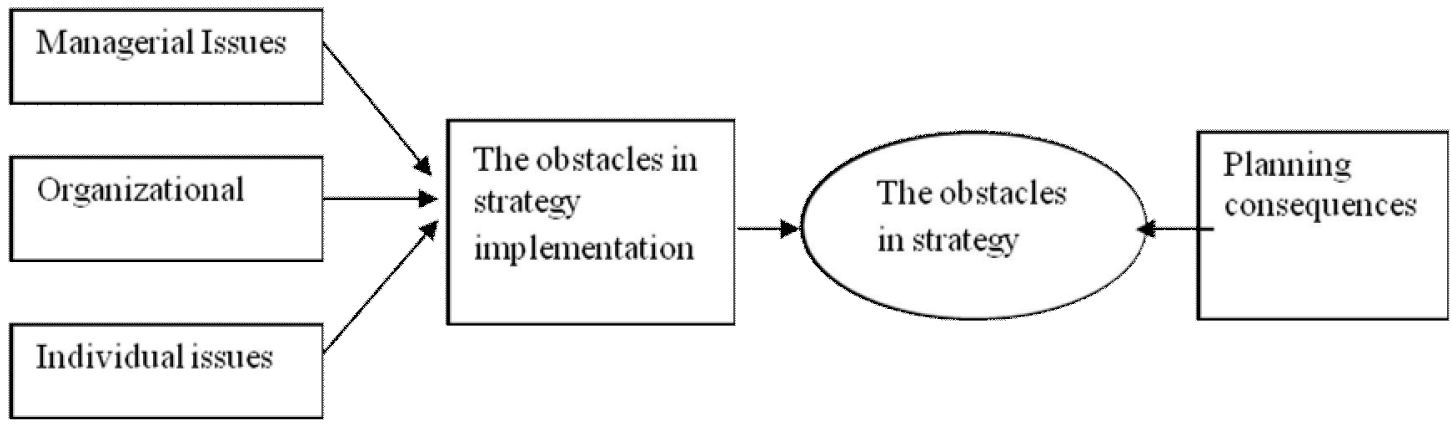

\section{Figure 1: Structural Equity Model}

\section{Methods}

The survey utilized in this study contained Alashloo, Castka \& Sharp's (2005) Impeders of Strategy Implementation scale. Demographic and personal items were also included, such as age, gender, management and organizational experience, and position in the firm, whether to participate in a strategy planning or implementation course. The sampling of the study consists of the managers of the organizations operating in Turkey. The sample included small and large organizations, domestic and global enterprises, and manufacturing and service firms. As questionnaire administration was a challenging task, pollster teams consisting of 50 voluntary students were formed and they administered the questionnaire to the top managers of the organizations through face-to-face interview method. In order to be able to achieve a high rate of return, pollster teams administered the questionnaire to the managers in their hometowns during the mid-term holiday. The data obtained from the questionnaire was sorted out SPSS 14.0 program package and their reliability analysis was conducted. Then, before the analyses of the hypotheses, the validity of the study was checked with confirmatory factor analysis and the hypotheses of the study were tested through Lisrel program package.

\section{Respondents}

The data were collected from managers in Turkey. 500 questionnaires were delivered to managers by pollster teams and 418 useful questionnaires were returned with an 83 percent response rate. Usable questionnaires were entered into Excel datasheet and analyzed with the use of SPSS 14 and Lisrel 8.80.

As presented in Table I, male managers accounted for $76,8 \%$ of the total participants, while female employees accounted for $23,2 \%$. In educational attainment, higher education accounted for $63,2 \%$ of the respondents. In management level, top managers accounted for $64,4 \%$ of the total number. The average age for the sample was 39.6 years, with respondents reporting 10,5 years of management experience and 8,9 years of experience with the present organization. 
Table 3: The Sample: Frequencies And Descriptive Data $(n=418)$

\begin{tabular}{|l|r|r|}
\hline Frequencies & \multicolumn{1}{|c|}{ N } & \multicolumn{1}{c|}{ \% } \\
\hline Gender & 321 & 76,8 \\
\hline Male & 97 & 23,2 \\
\hline Female & & \\
\hline Educational Attainment & 7 & 1,7 \\
\hline Primary & 124 & 29,7 \\
\hline Secondary & 264 & 63,2 \\
\hline Higher & 23 & 5,5 \\
\hline Master Degree & & \\
\hline Management Level & 25 & 6,0 \\
\hline Lower Manager & 124 & 29,7 \\
\hline Middle Managers & 269 & 64,4 \\
\hline Top Managers & & \\
\hline Training About Strategy Formulation \& Implementation & 218 & 52,2 \\
\hline Yes & 171 & 40,9 \\
\hline No & 29 & 6,9 \\
\hline Not Sure & & \\
\hline Descriptive Data (Mean \& Standard Deviation) & 39,6 & 8,3 \\
\hline Age & 10,5 & 6,3 \\
\hline Management Experience & & 6,2 \\
\hline Experience with Organization & & \\
\hline
\end{tabular}

Also, the organizations classification used by the European Union and the Association of Turkish Trade Chambers and Exchanges was employed (Altay \& Aksaraylý, 2007) as follows: 1-9 employees represent a micro-scale, 10-49 represent a small-scale, 50-249 represent a medium-scale and 250- up represent a large-scale. According to this classification, 9.8 percent of the organizations are micro-scale, 50,2 percent are small-scale, 17.0 percent are medium-scale organizations and 23.0 percent are large-scale organizations. With regards to industry, 36.6 percent of the organizations in the study operate in the service sector, 43.7 percent of the organizations in the study operate in industrial/manufacturing sector and the remaining 17.7 percent operate in fiscal/banking sector.

\section{Findings}

In order to be able to analyze the structural equation model, a two-stage confirmatory factor analysis was performed (Anderson \& Gerbing, 1988). Standard factor loadings (t-values) of the measurement model were brought in line with the modification indices resulting from the first-stage factor analysis are presented in Table 2, along with standard deviations and Cronbach' alpha values for each item of the measurement model. All of the alpha values exceed the minimum value of 0.70 (Nunnally, 1978). Mean values vary between 3 and 3,70. Values of all items are bigger than acceptable $t$ value (1.96 for $\mathrm{p}<0.05$ ), hence they are included in the SEM analysis. 
Table 4. Measurement model results And Means, Standart Deviation, Cronbach's alphas

\begin{tabular}{|c|c|c|c|c|c|}
\hline No & Scales \& Items & Std. factor load. & $\mathrm{t}$-value & Mean & SD \\
\hline $\mathbf{P}$ & Planning Consequences $(a ́=0,841)$ & & & & \\
\hline P1 & Lack of exact strategic planning & 0,61 & 15,42 & 3,36 & 1,15 \\
\hline $\mathrm{P} 2$ & Insufficient linking of the strategy to goals. & 0,56 & 12,95 & 3,38 & 1,06 \\
\hline P3 & Time limitation & 0,47 & 9,70 & 3,24 & 1,19 \\
\hline P4 & Lack of consensus among decision makers & 0,57 & 15,00 & 3,46 & 1,10 \\
\hline P5 & Lack of identification of major problems & 0,65 & 15,77 & 3,49 & 1,15 \\
\hline P6 & Lack of effective role formulators & 0,65 & 17,74 & 3,36 & 1,18 \\
\hline P7 & Unsuitable training system & 0,70 & 19,70 & 3,30 & 1,26 \\
\hline P8 & Unclear regulation and executive policies & 0,64 & 22,41 & 3,34 & 1,23 \\
\hline P9 & Lack of choice of real strategy & 0,56 & 17,15 & 3,47 & 1,16 \\
\hline P10 & Lack of a national attitude to strategy & 0,65 & 14,23 & 3,26 & 1,18 \\
\hline $\mathbf{O}$ & Organizational Issues $(\mathbf{a}=\mathbf{0 , 8 3 7})$ & & & & \\
\hline $\mathrm{O} 1$ & Incompatible structure with the strategy & 0,64 & 18,61 & 3,33 & 1,14 \\
\hline $\mathrm{O} 2$ & Unsuitable resources allocation & 0,62 & 16,67 & 3,35 & 1,16 \\
\hline $\mathrm{O} 3$ & Lack of adequate communication & 0,62 & 16,94 & 3,45 & 1,20 \\
\hline $\mathrm{O} 4$ & Lack of effective co-ordination & 0,58 & 14,43 & 3,47 & 1,15 \\
\hline $\mathrm{O} 5$ & Lack of adequate information system & 0,67 & 18,80 & 3,42 & 1,16 \\
\hline O6 & Incompatible organizational culture & 0,67 & 21,04 & 3,27 & 1,21 \\
\hline O7 & Competing activities among people & 0,42 & 8,58 & 3,51 & 1,08 \\
\hline O8 & Competing activities among units & 0,39 & 8,29 & 3,49 & 1,09 \\
\hline O9 & Unsuitable evaluation and control systems & 0,59 & 15,01 & 3,35 & 1,17 \\
\hline $\mathrm{O} 10$ & Unsuitable compensation system & 0,47 & 10,04 & 3,41 & 1,12 \\
\hline O11 & Inadequate physical facilities & 0,52 & 12,34 & 3,33 & 1,16 \\
\hline $\mathrm{O} 12$ & Lack of in creative system & 0,59 & 14,91 & 3,39 & 1,20 \\
\hline M & Managerial Issues $(\mathbf{a}=\mathbf{0 , 8 1 6})$ & & & & \\
\hline M1 & Unsuitable leadership & 0,63 & 17,02 & 3,31 & 1,21 \\
\hline M2 & Lack of adequate organizational support & 0,61 & 17,42 & 3,39 & 1,13 \\
\hline M3 & Lack of adequate manager commitment & 0,67 & 19,98 & 3,36 & 1,18 \\
\hline M4 & Fear of insecurity among managers & 0,59 & 14,58 & 3,37 & 1,16 \\
\hline M5 & Political factors in regard to power & 0,56 & 14,06 & 3,48 & 1,18 \\
\hline M6 & Unsuitable personnel management & 0,67 & 19,14 & 3,25 & 1,21 \\
\hline M7 & Uncontrollable factors & 0,50 & 11,25 & 3,49 & 1,02 \\
\hline M8 & Lack of enough motivation among the managers & 0,72 & 23,71 & 3,50 & 1,18 \\
\hline $\mathbf{I}$ & Individual Issues $(a ́=0,848)$ & & & & \\
\hline I1 & Lack of enough capabilities of employees & 0,70 & 21,79 & 3,41 & 1,17 \\
\hline $\mathrm{I} 2$ & Resistance to change among people & 0,62 & 17,62 & 3,45 & 1,15 \\
\hline $\mathrm{I} 3$ & Resistance to change among units & 0,59 & 15,87 & 3,41 & 1,14 \\
\hline $\mathrm{I} 4$ & Fear of insecurity in the new territory & 0,56 & 14,72 & 3,53 & 1,13 \\
\hline I5 & Lack of understanding of the strategy & 0,68 & 20,53 & 3,62 & 1,09 \\
\hline I6 & Inadequate connection to the vision & 0,71 & 23,49 & 3,46 & 1,11 \\
\hline I7 & Lack of enough motivation of employees & 0,70 & 21,46 & 3,62 & 1,18 \\
\hline I8 & Lack of employee commitment & 0,69 & 22,27 & 3,47 & 1,22 \\
\hline
\end{tabular}


Goodness-of-fit indices were found to be $\div^{2}: 1132,15$, df: 659, p: 0,00000, $\div^{2} / \mathrm{df:} 1.717$, Normed Fit Index (NFI): 0.968, Tucker-Lewis Index (TLI or NNFI): 0.985, Comparative Fit Index (CFI): 0.986 Root Mean Square Error of Approximation (RMSEA): 0.0415, and Goodness-of-fit indices of the measurement model were found to be acceptable levels.

The Maximum Likelihood (ML) SEM was employed. Goodness-of-fit indeces were found to be $\div^{2}$ : 1332,51, df: 760, p: 0.000, $\div^{2}$ /df: 1,7, Normed Fit Index (NFI): 0.846, Tucker-Lewis Index (TLI or NNFI): 0.975, Comparative Fit Index (CFI): 0.974 and Root Mean Square Error of Approximation (RMSEA): 0.033. The structural equation models are shown in Figure 2 with its standard factor loadings. The $\mathrm{t}$-value of the model is bigger than 1.96 .

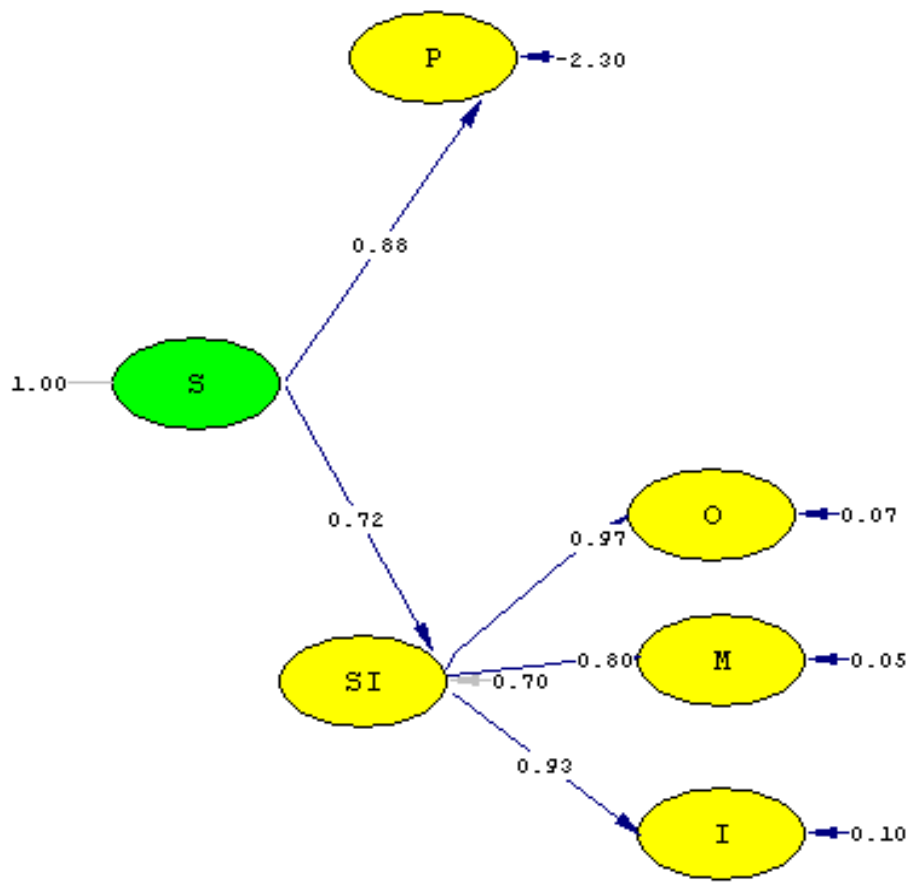

Chi-3quare $=1332.51, d f=760, P-v a l$ ue $=0.00000$, RMSE $\mathrm{a}=0.033$

\section{Fig. 2: Structural Model Results}

As can be seen from the results of Structural Model, standard factor loading value of strategy planning $(\mathrm{P})$ is higher than that of strategy implementation (SI). Hence, the biggest culprit for the failure of the strategies is the strategy formulation process. In this respect, the first hypothesis of the study "The factors relating strategy implementation process is more influential than those of strategy formulation process in explaining strategic failure" is refuted.

When we evaluate the factors affecting strategy implementation process for the second hypothesis, standard factor loading values are sequenced from the biggest to the smallest as "O" (organizational issue), "I" (individual issue) and "M" (managerial issue). Hence, the second hypothesis "The obstacles in front of the strategy implementation mostly stem from individual factors" is also refuted. 


\section{CONCLUSION AND RECOMMENDATION}

The present study focuses on the reasons for the failure of strategies. The success of strategies varies depending on the problems encountered in the formulation and implementation processes. In this respect, the present study reveals that planning process is a more important factor than implementation process in accounting for the failure of the strategies. The most important problems in the formulation process are "Lack of consensus among decision makers", "Lack of identification of major problems", "Lack of effective role formulators, "Unsuitable training system" and "Unclear regulation and executive policies." Moreover, it was found that the most important reason for the failure experienced during strategy implementation process is the organizational issues. The most commonly experienced problems concerning the organizational issues are "Incompatible organizational culture", "Competing activities among people", "Lack of adequate communication", "Lack of effective co-ordination" and "Lack of adequate information system".

It can be argued that there are two reasons leading us to these conclusions. First is that the Turkish managers do not know the techniques used in the strategic planning and hence they are not very willing to use them. Therefore, it can be argued that the most important reason for the failure of the strategies is the lack of training attempts. The second one is the cultural structure. Turkey reflects a collectivist culture and it is characterized as a high power distance culture (Hofstede, 1980, 1991). Lack of harmony between the cultural characteristics and organizational structure seems to be an important factor leading to failure. In this respect, organizational culture appears to be an important factor for the success of the strategies.

Another finding of this study is that all the factors mentioned are influential on the failure of the strategies followed by the Turkish organizations. In order to improve the situation, the workers should be provided with training on the strategy planning. In this way, many problems can be prevented from occurring by improving the capacities of the workers and leadership characteristics of the managers. Moreover, the organization should be structured in such a way as to open all the communications channels in the organization. Roles should be defined clearly so that no ambiguity will appear. Finally, all the tools that help the employees to participate in, understand and feel committed to strategy development should be adjusted to the organizational culture to be successful in the formulation and implementation of strategies.

The most important contribution of the present study to the literature and practice is to reveal that failure of the strategies is due to formulation process rather than implementation process. In light of the findings of the study, future research may seek answers to the following questions: "Do the factors causing strategies to be unsuccessful vary depending on the sector in which the organization is operating?", "Do the factors affecting the success of the organization vary depending on the size of the organization, the number of the staff, ownership structure, and age?" "What kind of relationship exists between the leadership characteristics and factors hindering successful implementation of strategies?" and "What is the relationship between factors affecting the successful implementation of strategies and performance?" and "Which preventive factors affect the performance more?". 


\section{REFERENCES}

Aaltonen, P., Ikavalko, H. (2002). Implementing strategies successfully, Integrated Manufacturing Systems, 13(6), 415- 418.

Al-Ghamdi, S. (1998), Obstacles to successful implementation of strategic decisions: the British experience, European Business Review, 98(6), 322-327.

Alashloo, F. R., Castka, P., Sharp, J. M., (2005), Towards Understanding the Impeders of Strategy Implementation in Higher Education (HE): A case of HE Institutes in Iran, Quality Assurance in Education, 13(2), 132-147.

Alexander, L. (1985), Successfully implementing strategic decisions, Long Range Planning, 18(3), 91-97.

Alexander, L.D. (1991), Strategy implementation: nature of the problem, in Hussey, D.E. (Ed.), International Review of Strategic Management, Vol. 2 No. 1 pp. 73-91.

Altay, A. \& Aksaraylı, M. (2007). KOBİ Destek Programlarının Kuramsal Boyutunun Analizi, 4. KOBÝ' ler ve Verimlilik Kongresi, İstanbul Kültür Üniversitesi, 7-8 Aralık, 35-49.

Beer, M. \& Eisenstat, R. (2000). The silent killers of strategy implementation and learning, Sloan Management Review, 41(4), 29-40.

Bryson, J. \& Bromiley, P. (1993). Critical factors affecting the planning and implementation of major projects, Strategic Management Journal, 14(2), 319-337.

Birnbaum, B. (2009). Strategy Implementation: Six Supporting Factors, www.birnbaumassociates.com/strategy-implementation.htm, 10.04.2009.

Corboy, M. \& O'Corrbui, D. (1999), The seven deadly sins of strategy, Management Accounting, November, 29-30.

David, F. R. (1989). Strategic Management, New Jersey: Prentice-Hall.

de Kluyver, C., \& Pearce, J., II. (2003). Strategy - a view from the top. Upper Saddle River, NJ: Prentice-Hall.

Dincer, O., Tatoðlu, E. \& Glaister, K. W. (2006). The strategic planning process: evidence from Turkish firms, Management Research News, 29(4), 206-219

Dobni, B. (2003). Creating a strategy implementation environment, Business Horizons, 46(2), 43-46.

Dooley, R. S., Fryxell, G. E. \& Judge, W. Q. (2000). Belaboring the Not-So-Obvious: Consensus, Commitment, and strategy implementation speed and success, Journal of Management, 26(6), 12371257.

Eisenstat, R. (1993), Implementing strategy developing a partnership for change, Planning Review, 21(5), 33-36.

Feo, J. A. D. \& Janssen, A. (2001), Implementing a strategy successfully, Measuring Business Excellence, 5 (4), 4-6. 
Freedman, M. (2003). The genius is in the implementation, Journal of Business Strategy, 24(2), 2631.

Galpin, T.J. (1998). When leaders really walk the talk: making strategy work through people, Human Resource Planning, 21(3), 38-45.

Giles, W.D. (1991). Making strategy work, Long Range Planning, 24(5), 75-91.

Hacker, M. \& Washington, M. (2004). How do we measure the implementation of large scale change?, Measuring Business Excellence, 8(3), 52- 59.

Harrington, R. J. (2004). The environment, involvement, and performance: Implications for the strategic process of food service firms, International Journal of Hospitality Management, 23(4), 317341 .

Harrington, R. J. \& Kendall, K. W. (2006). Strategy implementation Success: The moderating effects of size and environmental complexity and the mediating effects of involvement, Journal of Hospitality \& Tourism Research, 30(2), 207- 230.

Hofstede, G. (1991). Cultures and organizations: Software of the mind. London: McGraw-Hill.

Hofstede, G. (1980). Motivation, leadership and organization: Do American theories apply abroad? Organizational Dynamics, 9, 42-63.

Hrebiniak, L. G. (2005). Making Strategy Work: Leading Effective Execution and Change, Upper Saddle River: Pearson Education.

Hrebiniak, L. (1992). Implementing global strategies, European Management Journal, 10(4), 392395 .

Higgins, J.M. (2005). The eight 'S's of successful strategy execution, Journal of Change Management, 5(1), 3-13.

Higgs, M., \& Rowland, D. (2005, June). All changes great and small: Exploring approaches to change and its leadership, Journal of Change Management, 5(2), 121-152.

Hoag, B.G., Ritschard, H.V. \& Cooper, C.L. (2002), Obstacles to effective organisational change, Leadership and Organisation Development Journal, 23(1), 6-15.

Hofstede, G. (1991). Cultures and organizations: Software of the mind. London: McGraw-Hill.

Kargar, J. \& Blumenthal, R. A. (1994). Successful implementation of strategic decisions in small community banks, Journal of Small Business Managament, 32(2), 10-22.

Liedtka, J. (2006). Is your strategy a duck?, The Journal of Business Strategy, 27(5), 32-37.

Lingle, J. \& Schieman, W. (1994), Is data scatter subverting your strategy, Management Review, 83 (5), 53-56.

Okumuş, F., (2001). Towards a Strategy Implementation Framework, International Journal of Contemporary Hospitality Management, 13(7), 327-338.

Okumuş, F., (2003). A framework to implement strategies in organizations, Management Decision, 41(9), 871-882. 
Okumuş, F. \& Roper, A. (1999). A review of disparate approaches to strategy implementation in hospitality firms, Journal of Hospitality \& Tourism Research, 23(1), 21-39.

Parnell, J. A. (2008). Strategy execution in emerging economies: assessing strategic diffusion in Mexico and Peru, Management Decision, 46 (9), 1277-1298

Peng, W. \& Litteljohn, D. (2001). Organisational communication and strategy implementation - a primary inquiry, International Journal of Contemporary Hospitality Management, 13(7), 360-363.

Peters, T. H., Waterman, R. H., In Search of Excellence, New York: Haper Collins 1982.

Qi, H. (2005). Strategy Implementation: The Impact of Demographic Characteristics on the Level of Support Received by Middle Managers, Management International Review, 45(1), 45-70.

Raps, A. (2004). Implementing Strategy, Strategic Finance, 85 (12), 48-53.

Reid, D. M. (1989). Operationalizing strategic planning, Strategic Management Journal, 10, 553567.

Roth, K., Schweiger, M. \& Morrison, J. (1991). Global strategy implementation at unit level: operational capabilities and administrative mechanisms, Journal of International Business Studies, 22(3), 369-402.

Sandelands, E. (1994). All talk and no action? Perish the thought, Management Decision, 32(5), 1011 .

Schaap, J. I., (2006), Toward Strategy Implementation Success: An Emprical Study of the Role of Senior-Level Leaders in the Nevada Gaming Industry, UNLV Gaming Research \& Review Journal, 10(2), 13-37.

Schellenberg, D. S. (1983). Issues in strategy implementation: The effect of congruence among strategy, structure, and managerial performance criteria on organizational performance. Doctoral dissertation, Indiana University, IN.

Shah, A. M., 2005, The Foundations of Successful Strategy Implementation: Overcoming the Obstacles, Global Business Review, 6(2), 293-302.

Skivington, E.J. \& Daft, L.R. (1991). A study of organizational framework and process modalities for the implementation of business level strategic decisions, Journal of Management Studies, 28(1), 45-68.

Sterling, J. (2003). Translating strategy into effective implementation: Dispelling the myths and highlighting what Works, Strategy \& Leadership, 31(3), 27-34.

Taslak, S. (2004), Factors restricting success of strategic decisions : Evidence from the Turkish textile industry, European Business Review, Vol. 16, Iss. 2; pg. 152-164

Teare, R. E., Costa, J. \& eccles, G. (1998). Relating strategy, structure and performance, International Journal of Contemporary Hospitality Management, 10(2), 58-77.

Thompson, A., Jr., Gamble, J., \& Strickland, A., III. (2006). Strategy: Winning in the marketplace core concepts, analytical tools, cases (2nd ed.). Boston, MA: McGraw- Hill/Irwin. 
Thorpe, E. R. \& Morgan, R. E. (2007). In pursuit of the "ideal approach" to successful marketing strategy implementation, European Journal of Marketing, 41(5/6), 659-677.

Waterman, R.M., Peters, T. R., Phillips, J. R., 1988, Structure is Not Organization, in T.B. Quinn, H. Mintzberg, R.M. Jones (eds), The Strategy Process: Concepts, Contents and Case. New York: Prentice Hall.

Webster, F. E., 1981, Top Management's Concerns about Marketing, Journal of Marketing, Summer, 9-16.

Wheelen, T. L., and Hunger, D. J. (2006), Concepts in Strategic Management and Business Policy, Upper Saddle River: Pearson - Prentice Hall.

Wernham, R. (1984). Bridging the Awful Gap Between Strategy and Action, Long Range Planning, 17(6), 34-42.

Wessel, J. (1993), "The strategic human resource management process in practice", Planning $R e$ view, 21(5), 37-38.

Yip, O.S. (1992), Total Global Strategy, London: Prentice-Hall. 